\title{
The Effect of Three Mediterranean Diets on Remnant Cholesterol and Non-Alcoholic Fatty Liver Disease: A Secondary Analysis
}

\author{
Angelo Campanella ${ }^{1}{ }^{\mathbb{D}}$, Palma A. Iacovazzi ${ }^{2}$, Giovanni Misciagna ${ }^{3}$, Caterina Bonfiglio $^{1}$, \\ Antonella Mirizzi ${ }^{1}$, Isabella Franco ${ }^{1}$, Antonella Bianco ${ }^{1}$, Paolo Sorino ${ }^{1}$ (D), Maria G. Caruso ${ }^{4}$ (D), \\ Anna M. Cisternino ${ }^{4}$, Claudia Buongiorno ${ }^{1}\left(\mathbb{D}\right.$, Rosalba Liuzzi ${ }^{1}$ (D) and Alberto R. Osella ${ }^{1, *(D)}$ \\ 1 Laboratory of Epidemiology and Biostatistics, National Institute of Gastroenterology, “S. de Bellis" Research \\ Hospital, Castellana Grotte (Bari), Via Turi 27, 70013 Castellana Grotte, Italy; \\ angelocampanella7@gmail.com (A.C.); catia.bonfiglio@irccsdebellis.it (C.B.); \\ antonella.mirizzi@irccsdebellis.it (A.M.); isabella.franco@irccsdebellis.it (I.F.); \\ antonella.bianco@irccsdebellis.it (A.B.); paolosorino96@libero.it (P.S.); buongiorno.claudia@gmail.com (C.B.); \\ liuzzirosalba@libero.it (R.L.) \\ 2 Department of Clinical Pathology, National Institute of Gastroenterology, "S. de Bellis" Research Hospital, \\ Castellana Grotte (Bari), Via Turi 27, 70013 Castellana Grotte, Italy; mina.iacovazzi@irccsdebellis.it \\ 3 Scientific and Ethical Committee, University Hospital Policlinico, 70124 Bari, Italy; gmisciag@libero.it \\ 4 Ambulatory of Clinical Nutrition, National Institute of Gastroenterology, "S. de Bellis" Research Hospital, \\ Castellana Grotte (Bari), Via Turi 27, 70013 Castellana Grotte, Italy; gabriella.caruso@irccsdebellis.it (M.G.C.); \\ annamaria.cisternino@irccsdebellis.it (A.M.C.) \\ * Correspondence: arosella@irccsdebellis.it; Tel.: +39-080-499-4655
}

Received: 22 May 2020; Accepted: 2 June 2020; Published: 4 June 2020

\begin{abstract}
Background: Elevated fasting remnant cholesterol (REM-C) levels have been associated with an increased cardiovascular risk in patients with metabolic syndrome (Mets) and Non-Alcoholic Fatty Liver Disease (NAFLD). We aimed to estimate the effect of different diets on REM-C levels in patients with MetS, as well as the association between NAFLD and REM-C. Methods: This is a secondary analysis of the MEDIDIET study, a parallel-arm Randomized Clinical Trial (RCT). We examined 237 people with MetS who underwent Liver Ultrasound (LUS) to assess the NAFLD score at baseline, 3-, and 6-months follow-up. Subjects were randomly assigned to the Mediterranean diet (MD), Low Glycemic Index diet (LGID), or Low Glycemic Index Mediterranean diet (LGIMD). REM-C was calculated as [total cholesterol-low density lipoprotein cholesterol (LDL-C)-high density lipoprotein cholesterol (HDL-C)]. Results: REM-C levels were higher in subjects with moderate or severe NAFLD than in mild or absent ones. All diets had a direct effect in lowering the levels of REM-C after 3 and 6 months of intervention. In adherents subjects, this effect was stronger among LGIMD as compared to the control group. There was also a significant increase in REM-C levels among Severe NAFLD subjects at 3 months and a decrease at 6 months. Conclusions: fasting REM-C level is independently associated with the grade of severity of NAFLD. LGIMD adherence directly reduced the fasting REM-C in patients with MetS.
\end{abstract}

Keywords: fasting REM-C levels; NAFLD severity score; insulin resistance

\section{Introduction}

Hyperlipidemia is a condition characterized by elevated levels of serum lipids. Excess lipids in the blood commonly accumulate in the walls of arteries and several studies have established the central role of hyperlipidemia in the development of cardiovascular diseases (CVD) [1,2]. Other important 
studies have irrefutably demonstrated a strong relationship between hypercholesterolemia, mortality, and the incidence of CVD [3,4]. In particular, high Low-Density Lipoprotein levels (LDL-C), in combination with low High-Density Lipoprotein levels (HDL-C), are associated with an increased risk of atherosclerosis and ischemic heart disease.

Preventive measures, pharmacological therapy, and lifestyle changes have been focused on reducing LDL-C levels, which is currently the main target of lipid-lowering therapies [5-7]. However, even after a reduction of LDL-C to the recommended concentrations, there is still a considerable residual risk of recurrent cardiovascular events, so lowering LDL-C levels alone is insufficient [8]. Some of this residual risk may be attributed to elevated remnant cholesterol (REM-C) levels [9].

REM-C is the cholesterol content of triglyceride-rich lipoproteins, which in the fasting state include the Very Low-Density Lipoproteins (VLDL) and the Intermediate-Density Lipoproteins (IDL) produced by the liver. In the non-fasting state, REM-C also includes chylomicron remnants [10,11]. High levels of non-fasting plasma triglycerides are a marker of elevated non-fasting REM-C [10,12,13] and are associated with an increased risk of cardiovascular disease $[10,12,13]$. Since triglycerides per se are unlikely to have a direct role in provoking cardiovascular disease [12-16], REM-C is more likely to be the causal factor.

Irawati et al. (2016) [17] have shown a substantial accumulation of pro-atherogenic REM-C in subjects with metabolic syndrome (MetS), who are well known to be at risk of developing CVD. Increased plasma triglycerides and decreased HDL-C levels are typical components of MetS. Another condition associated with MetS is Non-Alcoholic Fatty Liver Disease (NAFLD), a potential independent CVD risk factor which leads to increases in liver fat, inflammation, and oxidative stress [18,19]. Indeed, the early manifestation of NAFLD is triglyceride accumulations in the liver associated with insulin resistance (IR) [20]. In patients with NAFLD, higher REM-C values were associated with greater liver disease severity and REM-C levels were found to be predictive of CVD [21].

Lifestyle changes, including dietary modifications (reducing carbohydrate and fat intake), physical activity, reducing alcohol intake, and weight loss, are the mainstay in the management of hypercholesterolemia and hypertriglyceridemia [22-24]. Several studies have been focused on the relationship between MetS and the Mediterranean diet, which features significant amounts of fibers, antioxidants, vegetable proteins, polyunsaturated, and monounsaturated fats. It has also been suggested that this way of eating decreases the risk of CVD and improves NAFLD [25]. These interventions have shown that the Mediterranean diet can reduce plasma triglyceride levels by up to $60 \%$ [22]. In adults, the Mediterranean Diet has also been demonstrated to be effective in reducing the risk of MetS [26,27].

In our Institution, a Randomized Clinical Trial (RCT) was conducted to estimate the effect of different diets on the MetS score and on its components after a six-month intervention period [28]. As no studies of the impact of diet on the relationship between REM-C and MetS have yet been reported, we aimed to estimate the effect of different diets on REM-C levels in patients with MetS, as well as the association between NAFLD and REM-C in patients enrolled in the RCT, by performing a secondary analysis [29].

\section{Materials and Methods}

\subsection{Study Design}

The original RCT is registered at https:/clinicaltrials.gov/, Identifier: NCT02356952 [30].

MEDIDIET was a parallel-arm RCT. Subjects with MetS were selected from the MICOL cohort study conducted at the National Institute of Gastroenterology "Saverio de Bellis" Research Hospital [31,32]. MICOL is an ongoing population study, which was started in 1985, including subjects randomly sampled (aged 30-89 years) from the electoral rolls of Castellana Grotte, a town in southern Italy (Apulia region). The cohort was followed up in 1992-1993 and in 2005-2006. In total, 2472 men and 
women were enrolled. In the second follow-up, the cohort was fed with 1273 randomly sampled young participants (30-49 years old) to compensate for aging of the cohort.

\subsection{Participants Selection}

Between December 2007 and April 2008, MICOL subjects who had been screened in 2005-2006 and had MetS (1042 subjects) were invited to undergo further examination: 556 subjects responded and 163 of 387 subjects (100 males, 63 females) were still affected by MetS. We included subjects treated with statins, anti-hypertensives, and oral antidiabetics, but excluded subjects in insulin treatment. Patients were requested not to change their exercise habits after enrollment in the study.

The trial was conducted in collaboration with General Practitioners, approved by the Ethics Committee of our Institution (D.Legs 502/92, Conv. N.54-2 marzo 2006) in accordance with the Helsinki Declaration, and all participants provided written informed consent.

\subsection{Randomization}

Participants were randomly assigned by simple randomization procedures (computerized random numbers sequence) to one of three diets or the Control group (C); a one-to-one ratio was used to allocate the subjects.

Blinding was maintained, firstly assuring the staff and participants that each diet was based on healthy principles. Participants were followed for the duration of the trial and the dietitian was assigned on a daily random basis. Moreover, only one intervention group was called in each day to reduce to a minimum the information exchange among participants. Staff members who assessed the outcomes were unaware of the diet assigned. Only one of two radiologists performed outcome measurements each day and this order was also randomly assigned. In the follow-up performed at the third and sixth months, the radiologists were unaware of the previous measurements.

\subsection{Baseline Examination}

Initial screening included a complete medical history and physical examination. Participants were asked to complete a structured questionnaire administered by a trained interviewer. Blood pressure at rest was measured by a trained nurse, using a sphygmomanometer with the appropriate cuff. Blood samples were drawn in the morning after overnight fasting and biochemical measurements were performed using standardized methods in the central laboratory of our institution. The serum was separated into two different aliquots. One aliquot was immediately stored at $-80{ }^{\circ} \mathrm{C}$. Anthropometric measurements (weight, height, waist circumference) were taken by three dietitians. Weight measurements were taken using SECA mechanical scales (Model 700; SECA, Hamburg, Germany), while height was measured using a wall-mounted altimeter (Model 206; $220 \mathrm{~cm}$; SECA, Hamburg, Germany). Dietitians also administered a validated semi-quantitative food frequency questionnaire [33] and carried out Bio-Impedentiometric Analysis (BIA) (Akern SRL, Pontassieve FI, Italy). Visceral Adiposity Thickness (VAT) was measured with Ultrasound scans using a strict protocol. It was defined as the distance between the anterior wall of the aorta and the internal face of the rectus abdominis muscle perpendicular to the aorta [34].

\subsection{Dietary Intervention}

The recommended diets were provided in brochure format, with graphical explanations organized according to a traffic light system: with a list of foods that can be consumed frequently (green foods), sometimes (yellow foods), and never (red foods). The brochure also contained a dietary record, where participants indicated daily the code of each food consumed at breakfast, lunch, dinner, and during snack time. There were no calorie restrictions. Diets composition is shown in Appendix A.

We studied the effects of the following diets: Mediterranean diet (MD), built using the Trichopoulou A. et al. study [35]; Low Glycemic Index diet (LGID) based on the Elia A. study [36], and Low Glycemic 
Index Mediterranean diet (LGIMD), created by integrating the Trichopolou A. et al. [35] and Elia A. studies [36] and adapting them to our population.

Individuals recorded what they ate on a daily diet diary. The main objectives pursued in the creation of the diets and the administration and monitoring tools were: (1) to let subjects choose their foods and (2) to help them monitor what they ate. The characteristics of the three diets and their main nutritional composition are described in Appendices A and B. Mean intake of Energy, Alcohol, and Macronutrients were calculated using Metadieta ${ }^{\circledR}$ software, version 3.7. Patients were asked not to change their physical activity after enrollment in the study.

Control group participants were only given general nutritional counseling and were advised to maintain their lifestyle. The control group was followed up with the same methodology.

\subsection{Outcomes}

In the protocol, primary outcome measures were MetS, MetS score, and its components. Secondary outcomes were anthropometric measurements and biochemical markers and Non-Alcoholic Fatty Liver Disease (NAFLD) score (measured by Liver Ultrasound (LUS)).

The quantitative serum levels of Total Cholesterol (TC), Triglycerides (TGL), Glucose (G), HDL-Cholesterol (HDL-C), and Insulin (INS) were evaluated using the UniCelDxC and DxI 660i Integrated System (Beckman Coulter, Fullerton, CA, USA). The timed endpoint method was used for chemicals and the chemiluminescent method for insulin. LDL-C was assessed using Friedewald's formula [37].

Insulin resistance and beta-cell function were estimated by the Homeostasis Model Assessment $($ HOMA) Index $=($ glucose $\times$ insulin $) / 22.5$ [38].

In accordance with the reference values routinely adopted in our laboratory, we considered out-of-range values as: total cholesterol $>5.18 \mathrm{mmol} / \mathrm{L}$, triglycerides $>1.86 \mathrm{mmol} / \mathrm{L}$, glucose $>$ $6.94 \mathrm{mmol} / \mathrm{L}, \mathrm{HDL}-\mathrm{C}<1.04 \mathrm{mmol} / \mathrm{L}$, insulin $>29 \mu \mathrm{IU} / \mathrm{mL}$, LDL-C $>3.88 \mathrm{mmol} / \mathrm{L}$, and HOMA $>2.5$.

REM-C was calculated as [total cholesterol-LDL-C-HDL-C] and we considered a value $>30 \mathrm{mg} / \mathrm{dL}$ as altered, in accordance with the literature for fasting REM-C [39].

\subsection{Implementation}

Subjects were followed up monthly for dietary counseling, to check diaries, and to control anthropometric parameters. After 12 and 24 weeks from the beginning of the study, the subjects again underwent fasting blood sampling and BIA.

\subsection{Statistical Analysis}

The primary analysis was intention-to-treat. Data were extensively described by means of Tables by using Mean $( \pm \mathrm{SD})$ and frequency $(\%)$ as descriptive measures for continuous and categorical variables, respectively.

The Mediterranean Adequacy Index (MAI) [40,41] was calculated to assess the compliance with the prescribed diet. Random week and week-end days were chosen from the second and fourth month of intervention. The MAI was estimated according to gender and month to clearly describe compliance. Compliance was defined as positive if the subject's ratio of percentage of calories derived from LGID or MD or LGIMD foods, divided by percentage of calories from foods not in the LGID, MD or LGIMD, was equal to or above the median value for the whole population under study. A median value of 7.5 with an inter-quantile range (IQR) of 5.4 was expected, as established by the reference Italian Mediterranean Diet [40]. An Analysis of Variance for repeated measures was performed to analyze the differences among group means (Diet by Time). This statistical technique was chosen because it is computationally elegant and relatively robust against violations of its assumptions, provides strong (multiple sample comparison) statistical analysis, and it has been adapted to the analysis of a variety of experimental designs. As REM-C was not normally distributed, a natural logarithmic transformation was applied. A post estimation procedure was then applied to contrast the estimated means by taking 
a reference category, in this case Control group at baseline. Margins statistics were calculated from predictions of a previously fit Analysis of Variance model and displayed graphically.

Statistical analysis was performed using Stata statistical software (version 16.1), StataCorp, 4905 Lakeway Drive, College Station, TX, USA (the Stata code is available upon request from the email: arosella@irccsdebellis.it).

\section{Results}

\section{Sample Description}

Participant characteristics are shown in Table 1. At Baseline, there was no significant difference for any of the variables considered among $C$ and the intervention groups (LGID, MD, and LGIMD). There were 61, 62, 57, and 57 subjects in the C, LGID, MD, and LGIMD groups, respectively. About $40 \%$ were females and the mean age was 57.6 (11.8) (men 56.8 (12.0), women 58.8 (11.3)). Mean age was 54.9 (13.9) for controls, 57.5 (10.7) for LGID, 59.4 (10.4) for MD, and 58.3 (9.8) for LGIMD. Baseline REM-C levels were slightly different among groups, but these differences did not reach statistical significance. Systolic Blood Pressure (SBP) and Diastolic Blood Pressure (DBP) were higher than the normal range. As expected, all subjects were obese with a BMI of about 33.0 for most groups and 34.93 for LIGMD. Biochemical markers other than REM-C were equally distributed among the control and intervention groups.

Table 1. Descriptive statistics (mean ( \pm standard deviation) or relative frequency $(\%)$ ) of the main characteristics of the participants by intervention and time.

\begin{tabular}{|c|c|c|c|c|c|}
\hline \multirow{3}{*}{ Variables * } & \multirow{3}{*}{ Time } & \multicolumn{4}{|c|}{ Diet } \\
\hline & & ${ }^{1} \mathrm{C}$ & ${ }^{2}$ LGID & ${ }^{3} \mathrm{MD}$ & ${ }^{4}$ LGIMD \\
\hline & & Mean (SD) & Mean (SD) & Mean (SD) & Mean (SD) \\
\hline $\mathrm{N}$ & & 61 & 62 & 57 & 57 \\
\hline Age (years) & & $59.15(12.76)$ & $57.50(10.44)$ & $59.07(10.83)$ & $57.81(9.77)$ \\
\hline \multicolumn{6}{|l|}{ Gender } \\
\hline Female & & $23(38 \%)$ & $25(40 \%)$ & $20(35 \%)$ & $25(44 \%)$ \\
\hline Male & & $38(62 \%)$ & $37(60 \%)$ & $37(65 \%)$ & $32(56 \%)$ \\
\hline \multirow{3}{*}{${ }^{5}$ REM-C (mmol/L) } & Baseline & $0.91(0.56)$ & $1.04(0.49)$ & $0.94(0.57)$ & $1.05(0.60)$ \\
\hline & 3 months & $0.81(0.38)$ & $0.87(0.58)$ & $0.80(0.32)$ & $0.84(0.46)$ \\
\hline & 6 months & $0.79(0.40)$ & $0.86(0.47)$ & $0.84(0.39)$ & $0.83(0.45)$ \\
\hline \multirow{3}{*}{${ }^{6} \mathrm{SBP}(\mathrm{Hg} \mathrm{mm})$} & Baseline & $135.90(16.75)$ & 139.35 (17.33) & $134.74(13.38)$ & 138.51 (17.58) \\
\hline & 3 months & $129.91(14.31)$ & $128.00(15.82)$ & $127.32(15.07)$ & $127.50(15.98)$ \\
\hline & 6 months & $127.50(11.35)$ & 125.88 (15.92) & $123.82(15.02)$ & $128.00(17.14)$ \\
\hline \multirow{3}{*}{${ }^{7} \mathrm{DBP}(\mathrm{Hg} \mathrm{mm})$} & Baseline & 84.18 (9.97) & $86.29(6.83)$ & $86.14(7.50)$ & 87.37 (7.97) \\
\hline & 3 months & $76.49(9.30)$ & $76.58(7.89)$ & $77.32(7.20)$ & $79.02(8.17)$ \\
\hline & 6 months & $76.46(8.05)$ & $77.32(9.39)$ & 75.88 (7.73) & $76.50(9.11)$ \\
\hline \multirow{3}{*}{${ }^{8} \mathrm{BMI}$} & Baseline & $33.19(4.33)$ & $33.42(6.68)$ & $33.05(3.83)$ & $34.92(5.75)$ \\
\hline & 3 months & $31.93(4.20)$ & $31.65(6.12)$ & $31.31(3.61)$ & $32.72(5.40)$ \\
\hline & 6 months & 31.15 (3.79) & $31.41(6.09)$ & $31.01(3.66)$ & $31.98(4.93)$ \\
\hline \multirow{3}{*}{${ }^{9} \mathrm{WC}(\mathrm{cm})$} & Baseline & $106.70(10.65)$ & $105.94(11.40)$ & $104.78(9.58)$ & $109.28(12.89)$ \\
\hline & 3 months & $104.56(10.02)$ & $102.35(10.89)$ & $101.55(9.34)$ & 105.68 (12.78) \\
\hline & 6 months & $104.85(9.21)$ & $102.04(10.82)$ & $101.36(9.26)$ & $104.51(11.48)$ \\
\hline \multirow{3}{*}{${ }^{10} \mathrm{TGL}(\mathrm{mmol} / \mathrm{L})$} & Baseline & $1.99(1.22)$ & $2.26(1.07)$ & $2.06(1.25)$ & $2.29(1.32)$ \\
\hline & 3 months & $1.77(0.83)$ & $1.90(1.27)$ & $1.75(0.70)$ & $1.84(1.00)$ \\
\hline & 6 months & $1.73(0.87)$ & $1.88(1.03)$ & $1.83(0.85)$ & $1.80(0.98)$ \\
\hline
\end{tabular}


Table 1. Cont

\begin{tabular}{|c|c|c|c|c|c|}
\hline \multirow{3}{*}{ Variables * } & \multirow{3}{*}{ Time } & \multicolumn{4}{|c|}{ Diet } \\
\hline & & ${ }^{1} \mathrm{C}$ & ${ }^{2}$ LGID & ${ }^{3} \mathrm{MD}$ & ${ }^{4}$ LGIMD \\
\hline & & Mean (SD) & Mean (SD) & Mean (SD) & Mean (SD) \\
\hline \multirow{3}{*}{$11 \mathrm{TC}(\mathrm{mmol} / \mathrm{L})$} & Baseline & $5.17(1.13)$ & $5.44(1.07)$ & $5.31(1.08)$ & $5.12(1.06)$ \\
\hline & 3 months & $4.98(1.03)$ & $5.04(1.13)$ & $5.01(0.81)$ & $5.00(0.90)$ \\
\hline & 6 months & $4.83(0.91)$ & $5.11(1.14)$ & $5.15(0.78)$ & $5.00(0.94)$ \\
\hline \multirow{3}{*}{12 HDL-C (mmol/L) } & Baseline & $1.27(0.33)$ & $1.22(0.25)$ & $1.23(0.24)$ & $1.20(0.33)$ \\
\hline & 3 months & $1.34(0.50)$ & $1.24(0.30)$ & $1.28(0.27)$ & $1.22(0.27)$ \\
\hline & 6 months & $1.17(0.31)$ & $1.26(0.23)$ & $1.27(0.26)$ & $1.24(0.30)$ \\
\hline \multirow{3}{*}{${ }^{13} \mathrm{LDL}-\mathrm{C}(\mathrm{mmol} / \mathrm{L})$} & Baseline & $2.98(0.86)$ & $3.18(0.89)$ & $3.14(0.82)$ & $2.90(0.95)$ \\
\hline & 3 months & $2.82(0.83)$ & $2.93(0.97)$ & $2.92(0.77)$ & $2.94(0.78)$ \\
\hline & 6 months & $2.86(0.72)$ & $2.98(0.94)$ & $3.03(0.82)$ & $2.93(0.87)$ \\
\hline \multirow{3}{*}{${ }^{14}$ HOMA-IR } & Baseline & $3.94(3.15)$ & $4.53(2.07)$ & $4.31(3.72)$ & $4.99(3.44)$ \\
\hline & 3 months & $3.44(2.61)$ & $3.26(1.67)$ & $2.97(1.53)$ & $3.55(2.54)$ \\
\hline & 6 months & $3.07(3.01)$ & $3.49(3.49)$ & $3.10(2.10)$ & $3.64(3.34)$ \\
\hline \multirow{3}{*}{15 VAT } & Baseline & $64.53(17.86)$ & $59.04(21.02)$ & $62.10(17.98)$ & $63.26(16.96)$ \\
\hline & 3 months & $56.58(16.21)$ & $53.97(14.74)$ & $54.70(15.30)$ & 57.03 (13.89) \\
\hline & 6 months & $56.89(17.20)$ & $54.34(13.71)$ & $55.07(14.85)$ & $59.94(18.42)$ \\
\hline \multirow{3}{*}{ Glucose (mmol/L) } & Baseline & $6.27(1.36)$ & $6.89(1.86)$ & $6.39(1.51)$ & $7.11(2.24)$ \\
\hline & 3 months & $5.83(1.18)$ & $5.98(0.89)$ & $5.78(1.25)$ & $6.37(1.67)$ \\
\hline & 6 months & $5.75(1.58)$ & $5.90(0.91)$ & $5.75(1.15)$ & $6.36(1.66)$ \\
\hline \multirow{3}{*}{${ }^{16}$ APO B (g/L) } & Baseline & $1.02(0.25)$ & $1.12(0.28)$ & $1.09(0.27)$ & $1.06(0.29)$ \\
\hline & 3 months & $0.91(0.27)$ & $0.94(0.31)$ & $0.95(0.26)$ & $0.98(0.29)$ \\
\hline & 6 months & $0.94(0.24)$ & $0.94(0.26)$ & $0.94(0.26)$ & $0.94(0.25)$ \\
\hline \multirow{3}{*}{${ }^{17} \mathrm{HbA} 1 \mathrm{c}(\mathrm{mmol} / \mathrm{mol})$} & Baseline & $5.66(0.56)$ & $6.16(1.09)$ & $5.92(0.90))$ & $6.42(1.42)$ \\
\hline & 3 months & $5.67(0.64)$ & $5.85(0.89)$ & $5.69(0.34)$ & $5.98(0.91)$ \\
\hline & 6 months & $5.54(0.56)$ & $5.76(0.59)$ & $5.67(0.56)$ & $5.97(0.84)$ \\
\hline \multicolumn{6}{|l|}{18 NCEP-ATP III criteria } \\
\hline \multirow{3}{*}{$0-2$} & Baseline & $19(31 \%)$ & $7(11 \%)$ & $12(21 \%)$ & $14(25 \%)$ \\
\hline & 3 months & $29(48 \%)$ & $25(40 \%)$ & $34(60 \%)$ & $23(40 \%)$ \\
\hline & 6 months & $28(46 \%)$ & $30(48 \%)$ & $30(53 \%)$ & $24(42 \%)$ \\
\hline \multirow{3}{*}{3} & Baseline & $26(43 \%)$ & $22(35 \%)$ & $26(46 \%)$ & $13(23 \%)$ \\
\hline & 3 months & $21(34 \%)$ & $24(39 \%)$ & $13(23 \%)$ & $15(26 \%)$ \\
\hline & 6 months & $10(16 \%)$ & $16(26 \%)$ & $15(26 \%)$ & $14(25 \%)$ \\
\hline \multirow{3}{*}{4} & Baseline & $12(20 \%)$ & $26(42 \%)$ & $18(32 \%)$ & $21(37 \%)$ \\
\hline & 3 months & $8(13 \%)$ & $12(19 \%)$ & $9(16 \%)$ & $13(23 \%)$ \\
\hline & 6 months & $22(36 \%)$ & $15(24 \%)$ & $12(21 \%)$ & $12(21 \%)$ \\
\hline \multirow{3}{*}{5} & Baseline & $4(7 \%)$ & $7(11 \%)$ & $1(2 \%)$ & $9(16 \%)$ \\
\hline & 3 months & $3(5 \%)$ & $1(2 \%)$ & $1(2 \%)$ & $6(11 \%)$ \\
\hline & 6 months & $1(2 \%)$ & $1(2 \%)$ & $0(0 \%)$ & $7(12 \%)$ \\
\hline
\end{tabular}

* No statistically significant difference among groups were found at baseline; ${ }^{1} \mathrm{C}$ : Control diet; ${ }^{2}$ LGID: Low Glycemic Index Diet; ${ }^{3}$ MD: Mediterranean Diet; ${ }^{4}$ LGIMD: Low Glycemic Index Mediterranean Diet; ${ }^{5}$ REM-C: Remnant Cholesterol; ${ }^{6}$ SBP: Systolic Blood Pressure; ${ }^{7}$ DBP: Diastolic Blood Pressure; ${ }^{8}$ BMI: Body Mass Index; ${ }^{9}$ WC: Waist Circumference; ${ }^{10}$ TGL: Triglycerides; ${ }^{11}$ TC: Total Cholesterol; ${ }^{12}$ HDL-C: High-Density Lipoprotein Cholesterol; ${ }^{13}$ LDL-C: Low-density Lipoprotein Cholesterol; ${ }^{14}$ HOMA-IR: Homeostasis model assessment for insulin resistance; 15 VAT: Visceral Adiposity Thickness; ${ }^{16}$ APO-B: Apolipoprotein B; ${ }^{17}$ HbA1c: Glycated Hemoglobin; ${ }^{18}$ NCEP-ATP III criteria: National Cholesterol Education Program (NCEP) Adult Treatment Panel (ATP) III criteria [42].

Overall, NAFLD prevalence in the sample was $82.28 \%$ and it was more prevalent in men $(88.89 \%)$ than in women (72.04\%). NAFLD severity grade was Absent (17.72\%), Mild (18.57\%), Moderate $(41.77 \%)$, and Severe $(21.94 \%)$. Men had more severe grades of NAFLD.

Table 2 shows descriptive statistics for NAFLD severity by Intervention group and Time. At baseline, in NAFLD absent subjects, REM-C in the control group was lower than in subjects who underwent dietary intervention, but this difference did not reach statistical significance. In all other categories of NAFLD, REM-C were equally distributed. 
Table 2. Remnant cholesterol levels by NAFLD severity and time in control subjects, whole sample, and adherent subjects.

\begin{tabular}{cccccccc}
\hline \multirow{2}{*}{ NAFLD $^{1}$} & \multirow{2}{*}{ Time } & \multicolumn{2}{c}{ Control Diet } & \multicolumn{2}{c}{ Intervention Subjects } & \multicolumn{2}{c}{ Adherent Subjects } \\
\cline { 3 - 7 } & & $\mathbf{N ~ ( \% )}$ & Mean (SD) & N (\%) & Mean (SD) & N (\%) & Mean (SD) \\
\hline \multirow{3}{*}{ Absent } & Baseline & $12(23.53)$ & $0.67(0.39)$ & $30(21.28)$ & $0.87(0.54)$ & $18(20.93)$ & $0.80(0.52)$ \\
& 3 months & $22(43.14)$ & $0.80(0.39)$ & $54(38.30)$ & $0.75(0.44)$ & $30(34.88)$ & $0.71(0.31)$ \\
& 6 months & $17(33.33)$ & $0.61(0.23)$ & $57(40.43)$ & $0.71(0.31)$ & $38(44.19)$ & $0.73(0.29)$ \\
\hline \multirow{3}{*}{ Mild } & Baseline & $14(37.84)$ & $0.94(0.38)$ & $30(27.78)$ & $0.95(0.57)$ & $20(25.32)$ & $0.93(0.38)$ \\
& 3 months & $12(32.43)$ & $0.79(0.32)$ & $44(40.74)$ & $0.77(0.46)$ & $33(41.77)$ & $0.72(0.30)$ \\
& 6 months & $11(29.73)$ & $0.92(0.45)$ & $34(31.48)$ & $0.76(0.43)$ & $26(32.91)$ & $0.71(0.34)^{*}$ \\
\hline \multirow{3}{*}{ Moderate } & Baseline & $24(45.28)$ & $0.96(0.71)$ & $75(44.91)$ & $1.05(0.50)$ & $45(45.45)$ & $1.08(0.56)$ \\
& 3 months & $15(28.30$ & $0.79(0.44)$ & $53(31.74)$ & $0.88(0.44)$ & $30(30.30)$ & $0.89(0.53)$ \\
& 6 months & $14(26.42)$ & $0.82(0.39)$ & $39(23.35)$ & $0.98(0.47)$ & $24(24.24)$ & $0.90(0.50)$ \\
\hline \multirow{3}{*}{ Severe } & Baseline & $11(44.0)$ & $1.02(0.52)$ & $41(46.07)$ & $1.09(0.63)$ & $17(48.57)$ & $1.25(0.81)$ \\
& 3 months & $8(32.0)$ & $0.90(0.39)$ & $21(23.60)$ & $1.10(0.53)$ & $7(20.00)$ & $1.37(0.67)$ \\
& 6 months & $6(24.0)$ & $1.03(0.54)$ & $27(30.34)$ & $1.03(0.51)$ & $11(31.43)$ & $1.23(0.65)$ \\
\hline
\end{tabular}

${ }^{1}$ NAFLD: Non-Alcoholic Fatty Liver Disease. ${ }^{*}$ Anova test $p<0.05$.

Overall, adherence to the prescribed diet was $72.82 \%$. The adherence was higher in women $(79.98 \%)$ than in men $(68.85 \%)$. Figure 1 shows the change over time of REM-C level by degree of NAFLD severity and type of intervention, both for the whole sample and for the adherent subjects. In the whole sample, there was a decreasing trend in REM-C levels in Absent or Mild NAFLD subjects for MD and LGIMD diets. The same trend was observed in subjects with moderate or severe NAFLD randomized to the MD diet. Instead, in adherent subjects, a decreasing trend was observed with the LGIMD diet for moderate or severe NAFLD.

Absent or Mild
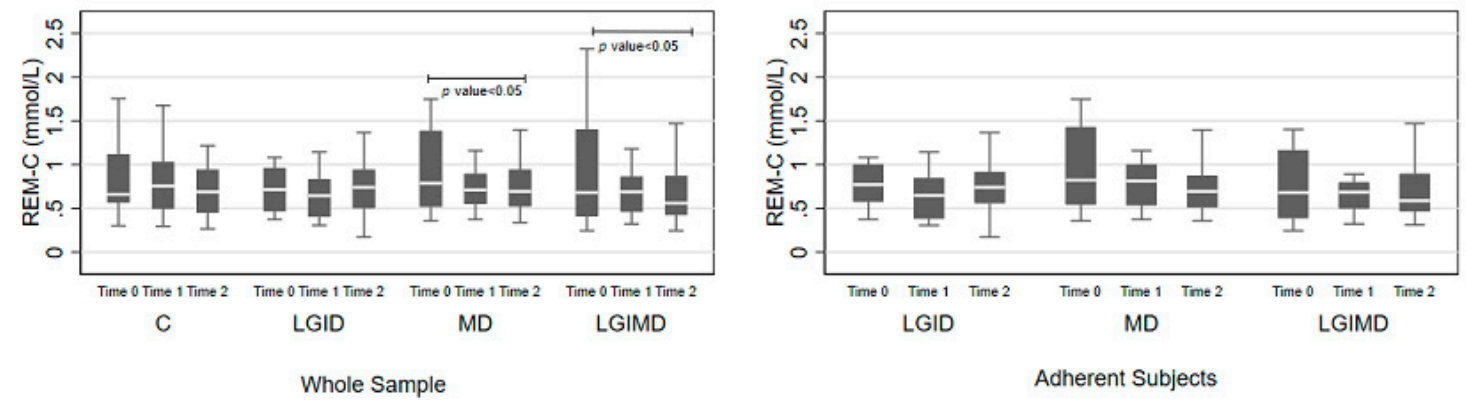

Moderate or Severe
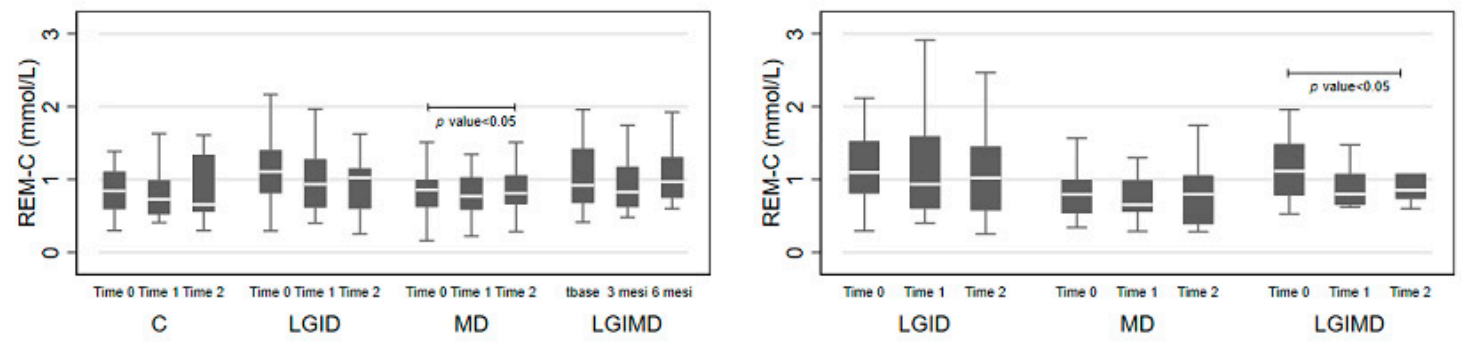

Whole Sample

Adherent Subjects

REM-C: Remnant Cholesterol; . Time 0: Baseline; Time 1: 3 months; Time 2: 6 months; C: Control Diet; LGID: Low Glycemic Index Diet, MD: Mediterranean Diet; LGIMD: Low Glycemic Index Mediteranean Diet

Figure 1. Remnant cholesterol level by non-alcoholic fatty liver disease severity, diet, and time.

Results from Repeated Measures Analysis of Variance for Diet and Time are shown in Table 3. In the whole sample, there were statistically significant principal effects for MD (-23.76, 95\%CI -43.97; $-3.56)$ and LGIMD $(-36.40,95 \%$ CI $-56.61 ;-16.20)$. Principal effects of Time were of small size and 
were not statistically significant. Statistically significant principal effects of Diets (increasing levels of REM-C) and Time were observed in adherent subjects. It is worth noting that among Adherent subjects, the referent value is the LGID.

Table 3. Repeated measures analysis of variance. Principal effects of diets and time and contrast of time within each level of diet in the whole sample and adherent subjects.

\begin{tabular}{|c|c|c|c|c|c|c|c|c|}
\hline \multirow{2}{*}{ Remnant Cholesterol } & \multicolumn{4}{|c|}{ Whole Sample } & \multicolumn{4}{|c|}{ Adherent Subjects } \\
\hline & $\beta$ & $\mathrm{SE}$ & $p$-Value & (CI 95\%) & $\beta$ & SE & $p$-Value & (CI 95\%) \\
\hline \multicolumn{9}{|l|}{ Diet } \\
\hline${ }^{2}$ LGID & -13.91 & 10.27 & 0.176 & $(-34.11 ; 6.28)$ & Referent & & & \\
\hline${ }^{3} \mathrm{MD}$ & -23.76 & 10.28 & 0.021 & $(-43.97 ;-3.56)$ & 37.02 & 10.39 & 0.000 & $(16.52 ; 57.51)$ \\
\hline${ }^{4}$ LGIMD & -36.40 & 10.28 & 0.000 & $(-56.61 ;-16.20)$ & 38.66 & 10.40 & 0.000 & $(18.15 ; 59.18)$ \\
\hline \multicolumn{9}{|l|}{ Time } \\
\hline 3 months & -3.04 & 2.32 & 0.190 & $(-7.56 ; 1.51)$ & -5.98 & 2.84 & 0.036 & $(-11.58 ;-0.38)$ \\
\hline 6 months & -1.55 & 2.47 & 0.532 & $(-6.41 ; 3.32)$ & -6.64 & 2.84 & 0.020 & $(-12.24 ;-1.04)$ \\
\hline \multicolumn{9}{|l|}{ Time \#Diet: } \\
\hline (3 Months vs. Baseline) \# C & -3.04 & 2.32 & 0.190 & $(-7.59 ; 1.51)$ & & & & \\
\hline (6 Months vs. Baseline) \# C & -1.55 & 2.47 & 0.532 & $(-6.41 ; 3.32)$ & & & & \\
\hline (3 Months vs. Baseline) \# LGID & -5.49 & 2.26 & 0.016 & $(-9.92 ;-1.05)$ & -5.98 & 2.84 & 0.036 & $(-11.58 ;-0.38)$ \\
\hline (6 Months vs. Baseline) \# LGIMD & -9.07 & 2.44 & 0.000 & $(-13.87 ;-4.28)$ & -12.18 & 3.19 & 0.000 & $(-18.48 ;-5.88)$ \\
\hline
\end{tabular}

\# by; ${ }^{1}$ C: Control diet; ${ }^{2}$ LGID: Low Glycemic Index Diet; ${ }^{3}$ MD: Mediterranean Diet; ${ }^{4}$ LGIMD: Low Glycemic Index Mediterranean Diet.

As regards the test of linear hypothesis, contrast of Time within each level of Diet evidenced a statistically significant effect for any contrast of Time (Three and Six months vs. Baseline) and Diet, except for Control Diet. These contrasts behaved in a similar way for both the whole sample and adherent subjects. These results are graphically displayed in Figure 2.

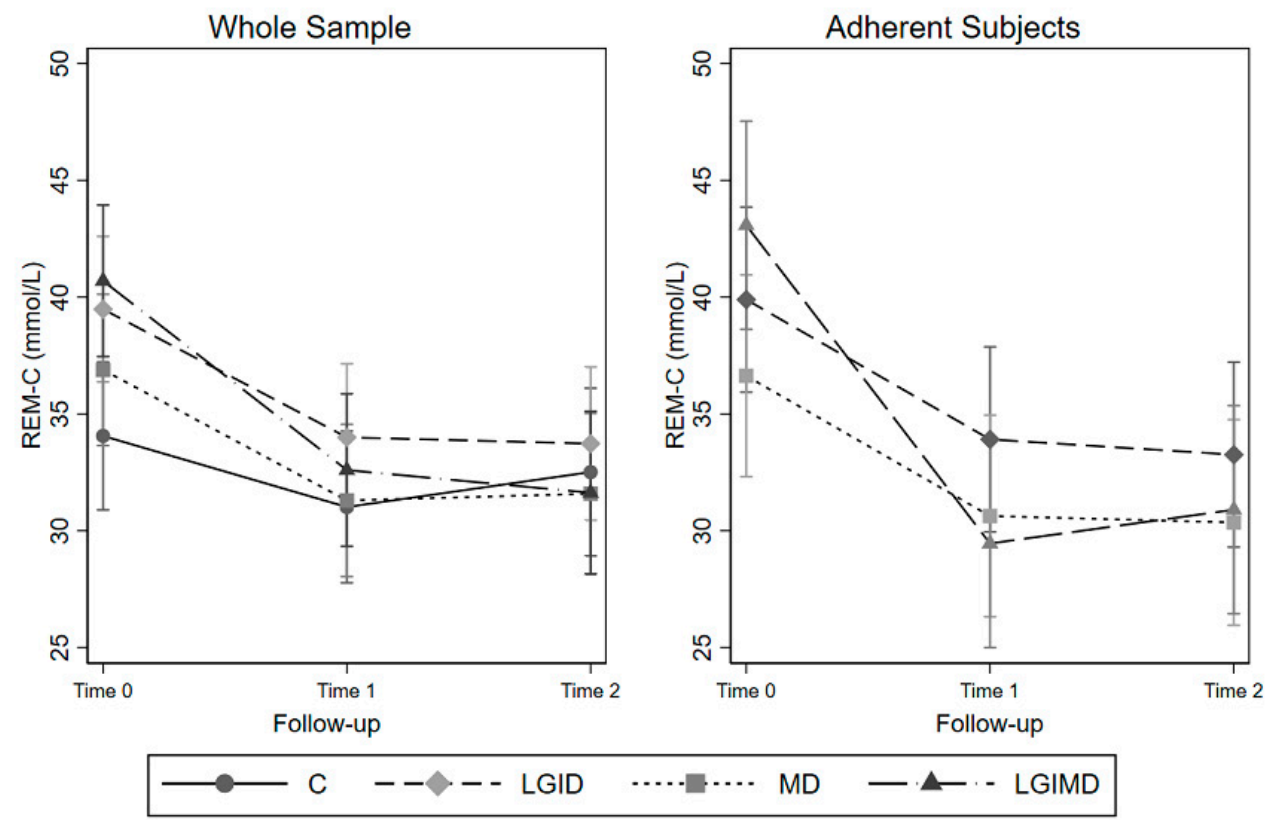

REM-C: Remnant Cholesterol. Time 0: Baseline; Time 1: 3 months; Time 2: 6 months

C: Control Diet; LGID: Low Glycemic Index Diet; MD: Mediterranean Diet; LGIMD: Low Glycemic Index Mediterranean Diet

Figure 2. Repeated measures analysis of variance. Marginal effects of diet and time on remnant cholesterol. 
Results from Repeated Measures Analysis of Variance for NAFLD Severity and Time are shown in Table 4. In the whole sample, there were no statistically significant principal effects for NAFLD severity, but there were statistically significant effects for Time. There was a statistically significant principal effect of NAFLD severity, but not a principal effect of Time.

Table 4. Repeated measures analysis of variance. Principal effects of NAFLD and time and contrast of time within each level of NAFLD in the whole sample and adherent subjects.

\begin{tabular}{|c|c|c|c|c|c|c|c|c|}
\hline \multirow{2}{*}{ Remnant Cholesterol } & \multicolumn{4}{|c|}{ Whole Sample } & \multicolumn{4}{|c|}{ Adherent Subjects } \\
\hline & $\beta$ & SE & $p$-Value & (CI 95\%) & $\beta$ & SE & $p$-Value & (CI 95\%) \\
\hline \multicolumn{9}{|l|}{${ }^{1}$ NAFLD } \\
\hline Mild & -15.47 & 12.15 & 0.204 & $(-39.41 ; 8.46)$ & 35.97 & 11.93 & 0.003 & $(12.27 ; 59.67)$ \\
\hline Moderate & -5.89 & 14.04 & 0.675 & $(-33.56 ; 21.77)$ & 41.27 & 13.04 & 0.002 & $(15.38 ; 67.15)$ \\
\hline Severe & 2.93 & 13.86 & 0.833 & $(-24.39 ; 30.24)$ & 23.00 & 11.80 & 0.054 & $(-0.41 ; 46.42)$ \\
\hline 3 months & -4.27 & 2.16 & 0.049 & $(-8.52 ;-0.019)$ & -4.56 & 3.26 & 0.165 & $(-11.03 ; 1.91)$ \\
\hline 6 months & -5.53 & 2.24 & 0.014 & $(-9.95 ;-1.11)$ & -5.13 & 3.32 & 0.126 & $(-11.73 ; 1.46)$ \\
\hline \multicolumn{9}{|l|}{ Time \# NAFLD: } \\
\hline (3 months vs. Baseline) Absent & -4.27 & 2.16 & 0.049 & $(-8.52 ;-0.019)$ & -4.56 & 3.26 & 0.165 & $(-11.03 ; 1.91)$ \\
\hline (6 months vs. Baseline) Absent & -5.53 & 2.24 & 0.014 & $(-9.95 ;-1.11)$ & -5.13 & 3.32 & 0.126 & $(-11.73 ; 1.46)$ \\
\hline ( 3 months vs. Baseline) Mild & -4.39 & 3.00 & 0.145 & $(-10.31 ; 1.52)$ & -5.46 & 3.80 & 0.154 & $(-13.01 ; 2.09)$ \\
\hline (6 months vs. Baseline) Severe & -0.26 & 3.43 & 0.940 & $(-7.01 ; 6.49)$ & 5.97 & 5.52 & 0.282 & $(-4.99 ; 16.94)$ \\
\hline
\end{tabular}

As regards the test of linear hypothesis, contrast of Time within each level of NAFLD severity evidenced a statistically significant effect for Time (three and six months) when NAFLD was Absent and for Moderate NAFLD at three months when the whole sample was considered. For Adherent Subjects, the contrast was statistically significant, but in an opposite way. For Moderate NAFLD, REM-C levels decreased at three and six months. Instead, in Severe NAFLD, there was a statistically significant increase in REM-C level at 3 months with a subsequent non statistically significant decrease at 6 months. Figure 3 displays the results for this analysis and it is possible to observe a positive association between increasing levels of REM-C and NAFLD severity.

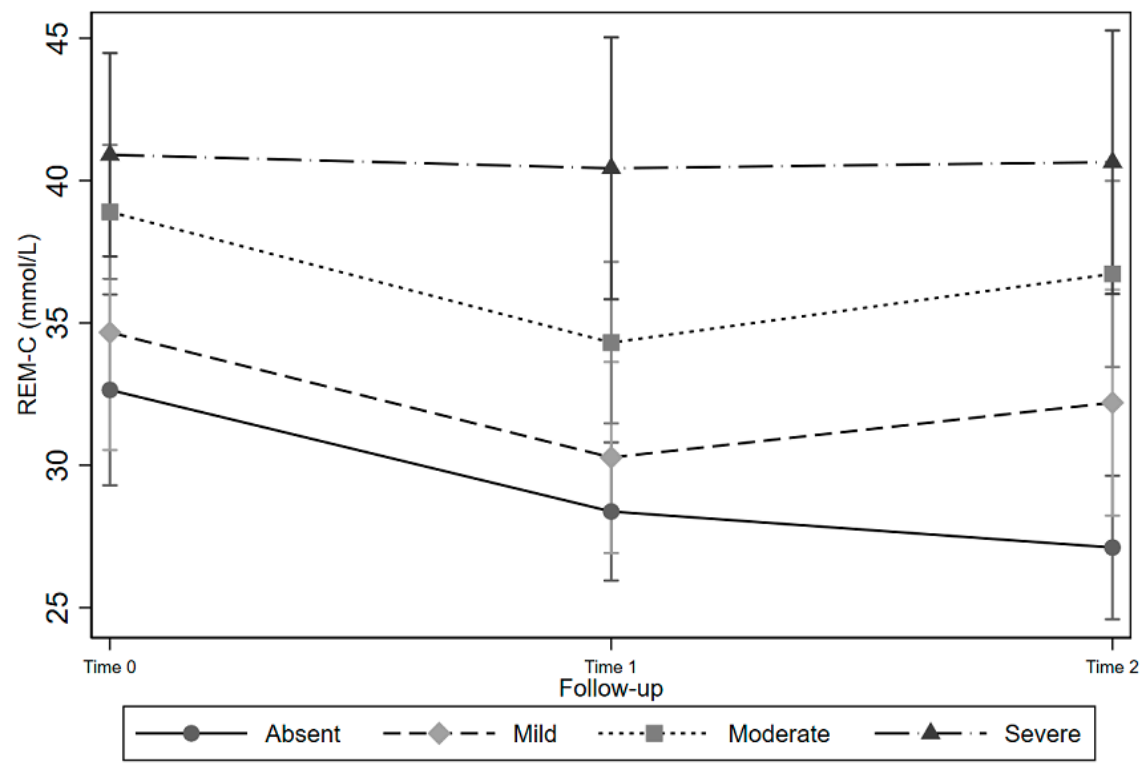

REM_C: Remnant Cholesterol. Time 0: Baseline; Time 1: 3 months; Time 2: 6 months.

Figure 3. Remnant cholesterol levels by non-alcoholic fatty liver disease severity and time. 


\section{Discussion}

In this research, all diets had a direct effect in lowering the levels of REM-C after 3 and 6 months of intervention in subjects with MetS. In adherent subjects, this effect was stronger mostly among LGIMD as compared to the control group.

Besides, REM-C levels were higher in subjects with moderate or severe NAFLD than in mild or absent ones, suggesting an association between liver metabolic function and REM-C: for the duration of the intervention, the less severe the degree of NAFLD, the lower the level of REM-C. Furthermore, while in the whole sample, there was a statistically significant decreasing trend among absent NAFLD and moderate NAFLD subjects. In the adherent group, the behavior was different: there was a statistically significant decreasing trend among moderate NAFLD subjects and a statistically significant increase at 3 months with a subsequent non significative decrease in the severe NAFLD subjects. These contrasting findings could be attributed to the role of diet in liver metabolism [43]. It is possible to speculate that some subjects had a higher intake of saturated fatty acids (SFA), although adherent to the diet. As shown in Appendix B (Table A1), the mean intake of SFAs in the LGIMD reached 15\% of total Kcal, while international guidelines recommend only $10 \%$ [44]. While greatly reducing the consumption of red and processed meat, the intake of SFAs and dietary cholesterol may have increased from the consumption of eggs, dairy products, and some fatty fish, such as mackerel. Although these products are typical of the Mediterranean diet, consumed in greater quantities, they may have worsened the NAFLD severity. There is evidence that SFAs reduce peripheral tissue sensitivity to insulin, while monounsaturated fatty acids (MUFA) can offset this effect $[45,46]$.

A relationship between dietary cholesterol and cardiovascular mortality is widely documented [47-49]. In particular, among the diet-related factors, SFAs have the greatest impact on LDL-C. An increase by $0.8-1.6 \mathrm{mg} / \mathrm{dL}$ of LDL-C is estimated for each $1 \%$ increase in SFAs intake [50]. Partially hydrogenated fatty acids are the main source of fats in foods of industrial origin, ranging from $2 \%$ to $5 \%$ of daily food intake in western countries. Their effect on LDL-C values is similar to that of SFAs [51]. Excess alcohol consumption is associated with increased adipocyte lipolysis and flow of Free Fatty Acids (FFAs) to the liver, resulting in increased VLDL production [52]. The western diet, characterized by an overconsumption of fructose, red meat, alcohol, soft drinks, and SFAs, in addition to a reduced intake of dietary fiber and omega-3 rich foods, displays an unfavorable relationship with the occurrence of NAFLD. This association may be explained by different mechanisms and attributed to each of the components that characterize this dietary pattern.

Our results show that changes in lifestyle and, in particular, eating habits are of great importance for the prevention and clinical management of MetS and NAFLD [43].

The Mediterranean way of eating is recommended for the treatment of NAFLD thanks to its potential to improve metabolic alterations such as insulin resistance and lipid profile, even without any accompanying weight loss [26]. The LGIMD owes its positive effects to the high intake of MUFA from extra virgin olive oil, polyunsaturated fatty acids (PUFA) from fish and nuts, fruit fibers, legumes and vegetables, as well as the reduced intake SFA and hydrogenated fatty acids. A greater intake of PUFA omega-3 and MUFAs are considered as beneficial since they limit inflammation and endothelial dysfunction and improve dyslipidemia [53,54]. In addition, replacing packaged and processed food with fresh food leads to a reduction in salt intake. Salt intake has also been suggested to be associated with an increased risk for NAFLD [25].

Furthermore, the greater intake of fiber and whole grains in LGID and LGIMD may have influenced the glycemic index control and, as a consequence, an improvement in the IR condition in NAFLD rather than in the MD diet. Moreover, the use of whole grains in LGID and LGIMD was fundamental in inducing further benefits on the cardiometabolic risk profile as they contain phenolic compounds, which increase antioxidant and anti-inflammatory activities $[55,56]$. Whole grains have the potential to beneficially influence the gut microbiota composition [57], which can be relevant due to the importance of the gut-liver axis in the onset and progression of NAFLD [58]. 
Subjects with severe NAFLD had the most impaired metabolic profile and showed significantly higher levels of REM-C at baseline. Our results are consistent with recent literature. In a prospective observational study, Pastori et al. (2018) [21] found that NAFLD was independently associated with higher serum fasting REM-C. In the same work, high REM-C levels were predictive of major adverse cardiovascular and cerebrovascular events in patients with NAFLD. In fact, it is known that subjects with NAFLD have prolonged metabolic disorders involving the glycemic and lipid balance. Dyslipidemia occurs with increased triglycerides, elevated atherogenic lipoproteins (LDL-C and VLDL-C), and reduced HDL-C levels. A glycemic imbalance develops, instead, with the condition of greater resistance to insulin. In this context, it was recently shown that patients with hepatic IR exhibited a higher postprandial triglyceride response than patients with muscle IR or without IR [59]. In the insulin resistant state, an increased lipolysis of adipocytes causes an increased flow of FFAs in the liver, which feeds APO-B lipidation, leading to an increase in VLDL production and de novo liver lipogenesis [60], which is ultimately shown by an increase in remnant cholesterol levels. As suggested by other studies, REM-C is a promising tool for CVD risk assessment since REM-C shares with LDL-C has the potential to enter and be trapped in the arterial wall, triggering plaque formation and progression [61,62].

Some methodological issues need to be considered. The strength of this study is the setting from which the population came from. One limitation of our work stems from the fact that calculated REM-C may not be as accurate as direct measurement, but it is difficult to assess all remnants components as it is more expensive and time consuming [63]. Therefore, calculated REM-C is an alternative approach to the direct measurement of REM-C, which has already been used in the studies of large Danish cohorts [10-16]. The fact that the sample size was not established based on the levels of REM-C can be criticized, but this is a secondary analysis and regardless, the sample came from the general population, so it is reasonable to think that it represents the true distribution of this marker.

\section{Conclusions}

In conclusion, fasting REM-C level is independently associated with the grade of severity of NAFLD and the improvement of the metabolic state of the liver and IR induced by the diet reduces the REM-C level. The Mediterranean dietary pattern may be a useful strategy for reducing the degree of NAFLD in patients with MetS and high-risk CVD to decrease the residual risk associated with REM-C. The LGIMD diet has proven to be more effective than other diets in reducing REM-C in the total sample. However, it is essential to control the SFA intake, especially in subjects with moderate and severe NAFLD.

Author Contributions: A.R.O. and A.C. contributed equally to the conception and design of the research; C.B., M.G.C., G.M., and P.S. contributed to the formal analysis; A.C., A.M., I.F., A.B., and A.M.C. contributed equally to the investigation; R.L. and C.B. contributed to the acquisition of the data; A.C. and P.A.I. drafted the manuscript; A.R.O. contributed to writing, reviewing, and editing the manuscript; A.R.O. supervision; A.R.O. project administration. All authors have read and agreed to the published version of the manuscript.

Funding: The study was supported by The Italian Minister of Health RC 2019 D.D.G. n. 74811 October 2018 and by Apulia Region-D.G.R. n. 1159, 28 June 2018 and 2019.

Acknowledgments: Carla M Leone, Pasqua L Pesole.

Conflicts of Interest: The authors declare no conflict of interest.

\section{Appendix A. Composition of the Diets}

Appendix A.1. Foods to Be Eaten Regularly

Mediterranean diet (MD)—Raw vegetables (lettuce, tomatoes, cucumbers, celery, carrots, radishes, etc.), steamed or boiled vegetables (beets, turnips, chicory, cauliflower, broccoli, etc.), fresh vegetables (peas, beans, green beans), pulses (lentils, chickpeas, beans, broad beans, soy), fish (anchovies, sardines, mackerel, etc.), cod, swordfish, fresh tuna, shellfish, canned tuna, bread, rice, pasta, tomato sauce, potatoes, extra virgin olive oil (raw), fresh fruits (apples, pears, oranges, grapefruit, 
kiwi, etc.), dried fruit (walnuts, almonds, dried figs: max 5 pieces), thick honey (pure), natural water, coffee (without sugar or artificial sweetener).

Low glycemic index diet (LGID) — Raw vegetables (lettuce, tomatoes, cucumbers, celery, carrots, radishes, etc.), steamed or boiled vegetables (beets, turnips, chicory, cauliflower, broccoli, etc.), fresh vegetables on their own (peas, green beans), pulses alone (lentils, chickpeas, beans, broad beans, soy), whole wheat pasta with vegetables, whole wheat pasta with vegetables, brown rice with legumes, brown rice with vegetables, extra virgin olive oil (raw), fish, mollusks, and crustaceans; canned tuna, unsweetened fresh fruit (apples, pears, oranges, grapefruit, kiwi, peaches, etc.), unsweetened nuts (walnuts, almonds: max 5 pieces), natural water, coffee (without sugar or with artificial sweetener).

Low glycemic index Mediterranean diet (LGIMD)—Raw vegetables (lettuce, tomatoes, cucumbers, celery, carrots, radishes, etc.), steamed or boiled vegetables (beets, turnips, chicory, cauliflower, broccoli, etc.), just fresh vegetables (peas, beans, green beans), pulses alone (lentils, chickpeas, beans, broad beans, soybeans), whole wheat pasta with vegetables, whole wheat pasta with vegetables, brown rice with vegetables; brown rice with vegetables, extra virgin olive oil (raw), fish (anchovies, sardines, mackerel, etc.), cod, swordfish, fresh tuna, shellfish, canned tuna, unsweetened fresh fruit (apples, pears, oranges, grapefruit, kiwi, peaches, etc.), unsweetened nuts (walnuts, almonds: max 5 pieces), natural water, coffee (without sugar or artificial sweetener).

\section{Appendix A.2. Foods to Be Eaten in Moderation}

MD—White meat (chicken, turkey, rabbit), milk and yogurt, dairy products (cheese, smoked cheese, ricotta), cheese (parmesan, pecorino cheese, etc.), eggs, dry biscuits and rusks, wine.

LGID-Whole wheat bread, whole wheat pasta with meat sauce; whole wheat pasta sauce, potatoes (read only), milk and yogurt, dairy products (cheese, smoked cheese, ricotta), cheese (parmesan, pecorino cheese, etc.), eggs, white meat (chicken, turkey, rabbit), red meat (beef, veal, pork, horse, etc.), salamis, sausages (raw or cooked ham, cured ham, salami, mortadella, etc.), sugary fruits (bananas, persimmons, grapes); pure thick honey; whole wheat biscuits, wine.

LGIMD - Whole wheat bread, whole wheat pasta with simple sauce, potatoes (read only), milk and yogurt, dairy products (cheese, smoked cheese, cottage cheese), cheese (parmesan, cheese, etc.), eggs, white meat (chicken, turkey, rabbit), sugary fruit (bananas, persimmons, grapes); pure thick honey, whole wheat biscuits, wine.

\section{Appendix A.3. Foods to Be Avoided Completely}

MD—Red meat (beef, veal, pork, horse, etc.) sauce, canned meat, sausages, cured meats (raw or cooked ham, dried beef, bacon, salami, mortadella, etc.); farmed fish, butter, margarine, mayonnaise, cream, pizza, french fries or baked-goods, crackers, pretzels, bread sticks, set them, cakes and breakfast cereals, sugar, jam, fruit syrup and candied chocolate candies, cakes, pastries, croissants, shortbread, biscuits, ice cream, and ices; alcoholic beverages and spirits (brandy, grappa, liqueurs, whiskey), non-carbonated soft drinks (orange juice, coca-cola, fruit juice, etc.), and beer.

LGID—Refined foods, white rice, white bread, pizza, french fries or baked goods, crackers, pretzels, bread sticks, bread and breakfast cereals, butter, margarine, mayonnaise, cream, sweet dried fruit (dried figs, dried dates, prunes, raisins), fruit in syrup and candied sugar, jams, candies and chocolates, cakes, sweets, pastries; croissants, pastries and cakes, shortbread, biscuits, dry biscuits, toast, ice cream and ices; alcoholic beverages and spirits (brandy, grappa, liqueurs, whiskey), non-alcoholic and non-carbonated (orange juice, coca-cola, fruit juice, etc.) beverages, and beer.

LGIMD-Refined pasta, white rice, white bread, pizza, french fries or baked goods, crackers, pretzels, bread sticks, bread and breakfast cereals, butter, margarine, mayonnaise, cream, red meat (beef, veal, pork, horse, etc.) sauce, canned meat, sausages (raw or cooked ham, dried beef, bacon, salami, mortadella, etc.), farmed fish, sweet dried fruit (dried figs, dried dates, prunes, raisins), fruit in syrup and candied sugar, jams, candies and chocolates, cakes, sweets, pastries, croissants, pastries and cakes, shortbread, biscuits, dry biscuits, toast, ice cream and ices; alcoholic beverages and spirits 
(brandy, grappa, liqueurs, whiskey), non-carbonated soft drinks (orange juice, coca-cola, fruit juice, etc.), and beer.

Each diet leaflet included 28 pages. On the first page, there was the introduction, instructions for completing the food diary, and a detailed list of recommended foods. The subsequent pages were used to record the daily diet for the period of the study and thus, to allow assessment of the level of compliance with the recommended diet.

\section{Appendix B}

Table A1. Energy and nutrients intake in the Mediterranean Diet (MD) Low Glycemic Index Diet (LGID) and Low Glycemic Index Mediterranean Diet (LGIMD).

\begin{tabular}{cccc}
\hline & \multicolumn{3}{c}{ Diet } \\
\cline { 2 - 4 } & MD $^{\mathbf{1}}$ & LGID $^{\mathbf{2}}$ & LGIMD $^{\mathbf{3}}$ \\
\hline Caloric intake (kcal/die) & 1532 & 1537 & 1521 \\
Proteins (\%) & 15.9 & 18.2 & 16.7 \\
Fats (\%) & 37.3 & 33.3 & 41.8 \\
Carbohydrates (\%) & 45.4 & 46.5 & 39.7 \\
Starch (g/die) & 111 & 62 & 45 \\
Fibers (g/die) & 18.5 & 24.0 & 23.2 \\
Alcohol (g/die) & 9.9 & 6.9 & 9.2 \\
Monounsaturated fatty acids (g/die) & 33.3 & 32.0 & 37.1 \\
Polyunsaturated fatty acids (g/die) & 8.3 & 7.4 & 8.8 \\
Saturated fatty acids (g/die) & 21.9 & 17.5 & 24.6 \\
\hline
\end{tabular}

${ }^{1}$ MD: Mediterranean Diet; ${ }^{2}$ LGID: Low Glycemic Index Diet; ${ }^{3}$ LGIMD: Low Glycemic Index Mediterranean Diet.

\section{References}

1. Mozaffarian, D.; Benjamin, E.J.; Go, A.S.; Arnett, D.K.; Blaha, M.J.; Cushman, M.; Das, S.R.; de Ferranti, S.; Despres, J.P.; Fullerton, H.J.; et al. Heart Disease and Stroke Statistics-2016 Update: A Report From the American Heart Association. Circulation 2016, 133, e38. [CrossRef] [PubMed]

2. Lewington, S.; Whitlock, G.; Clarke, R.; Sherliker, P.; Emberson, J.; Halsey, J.; Qizilbash, N.; Peto, R.; Collins, R. Blood cholesterol and vascular mortality by age, sex, and blood pressure: A meta-analysis of individual data from 61 prospective studies with 55,000 vascular deaths. Lancet 2007, 370, 1829-1839. [CrossRef] [PubMed]

3. Multiple Risk Factor Intervention Trial. Risk factor changes and mortality results. Multiple Risk Factor Intervention Trial Research Group. JAMA 1982, 248, 1465-1477. [CrossRef]

4. Chen, G.; Levy, D. Contributions of the Framingham Heart Study to the Epidemiology of Coronary Heart Disease. JAMA Cardiol. 2016, 1, 825-830. [CrossRef] [PubMed]

5. Jacobson, T.A.; Maki, K.C.; Orringer, C.E.; Jones, P.H.; Kris-Etherton, P.; Sikand, G.; La Forge, R.; Daniels, S.R.; Wilson, D.P.; Morris, P.B.; et al. National Lipid Association Recommendations for Patient-Centered Management of Dyslipidemia: Part 2. J. Clin. Lipidol. 2015, 9, S1-S122.e121. [CrossRef] [PubMed]

6. Arnett, D.K.; Blumenthal, R.S.; Albert, M.A.; Buroker, A.B.; Goldberger, Z.D.; Hahn, E.J.; Himmelfarb, C.D.; Khera, A.; Lloyd-Jones, D.; McEvoy, J.W.; et al. 2019 ACC/AHA Guideline on the Primary Prevention of Cardiovascular Disease: A Report of the American College of Cardiology/American Heart Association Task Force on Clinical Practice Guidelines. Circulation 2019, 140, e596-e646. [CrossRef]

7. Mach, F.; Baigent, C.; Catapano, A.L.; Koskinas, K.C.; Casula, M.; Badimon, L.; Chapman, M.J.; De Backer, G.G.; Delgado, V.; Ference, B.A.; et al. 2019 ESC/EAS Guidelines for the management of dyslipidaemias: Lipid modification to reduce cardiovascular risk. Eur. Heart J. 2019. [CrossRef]

8. Sampson, U.K.; Fazio, S.; Linton, M.F. Residual cardiovascular risk despite optimal LDL cholesterol reduction with statins: The evidence, etiology, and therapeutic challenges. Curr. Atheroscler. Rep. 2012, 14, 1-10. [CrossRef]

9. Varbo, A.; Benn, M.; Tybjaerg-Hansen, A.; Jorgensen, A.B.; Frikke-Schmidt, R.; Nordestgaard, B.G. Remnant cholesterol as a causal risk factor for ischemic heart disease. J. Am. Coll. Cardiol. 2013, 61, 427-436. [CrossRef] 
10. Nordestgaard, B.G.; Benn, M.; Schnohr, P.; Tybjaerg-Hansen, A. Nonfasting triglycerides and risk of myocardial infarction, ischemic heart disease, and death in men and women. JAMA 2007, 298, 299-308. [CrossRef]

11. Chapman, M.J.; Ginsberg, H.N.; Amarenco, P.; Andreotti, F.; Boren, J.; Catapano, A.L.; Descamps, O.S.; Fisher, E.; Kovanen, P.T.; Kuivenhoven, J.A.; et al. Triglyceride-rich lipoproteins and high-density lipoprotein cholesterol in patients at high risk of cardiovascular disease: Evidence and guidance for management. Eur. Heart J. 2011, 32, 1345-1361. [CrossRef] [PubMed]

12. Langsted, A.; Freiberg, J.J.; Tybjaerg-Hansen, A.; Schnohr, P.; Jensen, G.B.; Nordestgaard, B.G. Nonfasting cholesterol and triglycerides and association with risk of myocardial infarction and total mortality: The Copenhagen City Heart Study with 31 years of follow-up. J. Intern. Med. 2011, 270, 65-75. [CrossRef] [PubMed]

13. Varbo, A.; Nordestgaard, B.G.; Tybjaerg-Hansen, A.; Schnohr, P.; Jensen, G.B.; Benn, M. Nonfasting triglycerides, cholesterol, and ischemic stroke in the general population. Ann. Neurol. 2011, 69, 628-634. [CrossRef] [PubMed]

14. Bansal, S.; Buring, J.E.; Rifai, N.; Mora, S.; Sacks, F.M.; Ridker, P.M. Fasting compared with nonfasting triglycerides and risk of cardiovascular events in women. JAMA 2007, 298, 309-316. [CrossRef]

15. Miller, M.; Stone, N.J.; Ballantyne, C.; Bittner, V.; Criqui, M.H.; Ginsberg, H.N.; Goldberg, A.C.; Howard, W.J.; Jacobson, M.S.; Kris-Etherton, P.M.; et al. Triglycerides and cardiovascular disease: A scientific statement from the American Heart Association. Circulation 2011, 123, 2292-2333. [CrossRef]

16. Freiberg, J.J.; Tybjaerg-Hansen, A.; Jensen, J.S.; Nordestgaard, B.G. Nonfasting triglycerides and risk of ischemic stroke in the general population. JAMA 2008, 300, 2142-2152. [CrossRef]

17. Irawati, D.; Mamo, J.C.; Dhaliwal, S.S.; Soares, M.J.; Slivkoff-Clark, K.M.; James, A.P. Plasma triglyceride and high density lipoprotein cholesterol are poor surrogate markers of pro-atherogenic chylomicron remnant homeostasis in subjects with the metabolic syndrome. Lipids Health Dis. 2016, 15, 169. [CrossRef]

18. Satapati, S.; Kucejova, B.; Duarte, J.A.; Fletcher, J.A.; Reynolds, L.; Sunny, N.E.; He, T.; Nair, L.A.; Livingston, K.A.; Fu, X.; et al. Mitochondrial metabolism mediates oxidative stress and inflammation in fatty liver. J. Clin. Investig. 2015, 125, 4447-4462. [CrossRef]

19. Satapati, S.; Kucejova, B.; Duarte, J.A.; Fletcher, J.A.; Reynolds, L.; Sunny, N.E.; He, T.; Nair, L.A.; Livingston, K.A.; Fu, X.; et al. Mitochondrial metabolism mediates oxidative stress and inflammation in fatty liver. J. Clin. Investig. 2016, 126, 1605. [CrossRef]

20. Gaggini, M.; Morelli, M.; Buzzigoli, E.; DeFronzo, R.A.; Bugianesi, E.; Gastaldelli, A. Non-alcoholic fatty liver disease (NAFLD) and its connection with insulin resistance, dyslipidemia, atherosclerosis and coronary heart disease. Nutrients 2013, 5, 1544-1560. [CrossRef]

21. Pastori, D.; Baratta, F.; Novo, M.; Cocomello, N.; Violi, F.; Angelico, F.; Del Ben, M. Remnant Lipoprotein Cholesterol and Cardiovascular and Cerebrovascular Events in Patients with Non-Alcoholic Fatty Liver Disease. J. Clin. Med. 2018, 7, 378. [CrossRef] [PubMed]

22. Watts, G.F.; Ooi, E.M.; Chan, D.C. Demystifying the management of hypertriglyceridaemia. Nat. Rev. Cardiol. 2013, 10, 648-661. [CrossRef] [PubMed]

23. Dattilo, A.M.; Kris-Etherton, P.M. Effects of weight reduction on blood lipids and lipoproteins: A meta-analysis. Am. J. Clin. Nutr. 1992, 56, 320-328. [CrossRef] [PubMed]

24. Appel, L.J.; Sacks, F.M.; Carey, V.J.; Obarzanek, E.; Swain, J.F.; Miller, E.R., 3rd; Conlin, P.R.; Erlinger, T.P.; Rosner, B.A.; Laranjo, N.M.; et al. Effects of protein, monounsaturated fat, and carbohydrate intake on blood pressure and serum lipids: Results of the OmniHeart randomized trial. JAMA 2005, 294, 2455-2464. [CrossRef]

25. Zelber-Sagi, S.; Salomone, F.; Mlynarsky, L. The Mediterranean dietary pattern as the diet of choice for non-alcoholic fatty liver disease: Evidence and plausible mechanisms. Liver Int. Off. J. Int. Assoc. Study Liver 2017, 37, 936-949. [CrossRef]

26. Sofi, F.; Abbate, R.; Gensini, G.F.; Casini, A. Accruing evidence on benefits of adherence to the Mediterranean diet on health: An updated systematic review and meta-analysis. Am. J. Clin. Nutr. 2010, 92, 1189-1196. [CrossRef]

27. Kastorini, C.M.; Milionis, H.J.; Esposito, K.; Giugliano, D.; Goudevenos, J.A.; Panagiotakos, D.B. The effect of Mediterranean diet on metabolic syndrome and its components: A meta-analysis of 50 studies and 534,906 individuals. J. Am. Coll. Cardiol. 2011, 57, 1299-1313. [CrossRef] 
28. Osella, A.R.; Colaianni, G.; Correale, M.; Pesole, P.L.; Bruno, I.; Buongiorno, C.; Deflorio, V.; Leone, C.M.; Colucci, S.C.; Grano, M.; et al. Irisin serum levels in metabolic syndrome patients treated with three different diets: A post-hoc analysis from a randomized controlled clinical trial. Nutrients 2018, 10, 844. [CrossRef]

29. Franco, I.; Bianco, A.; Dìaz, M.D.P.; Bonfiglio, C.; Chiloiro, M.; Pou, S.A.; Becaria Coquet, J.; Mirizzi, A.; Nitti, A.; Campanella, A.; et al. Effectiveness of two physical activity programs on non-alcoholic fatty liver disease. a randomized controlled clinical trial. Rev. Fac. Cienc. Médicas Córdoba 2019, 76, 26. [CrossRef]

30. ClinicalTrials.gov is a Database of Privately and Publicly Funded Clinical Studies Conducted around the World. Available online: https://www.clinicaltrials.gov/ (accessed on 24 February 2020).

31. Misciagna, G.; Leoci, C.; Guerra, V.; Chiloiro, M.; Elba, S.; Petruzzi, J.; Mossa, A.; Noviello, M.R.; Coviello, A.; Minutolo, M.C.; et al. Epidemiology of cholelithiasis in southern Italy. Part II: Risk factors. Eur. J. Gastroenterol. Hepatol. 1996, 8, 585-593. [CrossRef]

32. Osella, A.R.; Misciagna, G.; Leone, A.; Di Leo, A.; Fiore, G. Epidemiology of hepatitis C virus infection in an area of Southern Italy. J. Hepatol. 1997, 27, 30-35. [CrossRef]

33. Leoci, C.C.S.; Guerra, V.; Cisternino, A.M.; Misciagna, G. Validazione e riproducibilità di un questionario di frequenza alimentare semi-quantitativo autosomministrato (Reliability and validity of a self administered semi-quantitative food frequency questionnaire.). Giorn. Ital. Nutr. Clin. Prev. 1993, 71, 1269-1324.

34. Kim, S.K.; Kim, H.J.; Hur, K.Y.; Choi, S.H.; Ahn, C.W.; Lim, S.K.; Kim, K.R.; Lee, H.C.; Huh, K.B.; Cha, B.S. Visceral fat thickness measured by ultrasonography can estimate not only visceral obesity but also risks of cardiovascular and metabolic diseases. Am. J. Clin. Nutr. 2004, 79, 593-599. [CrossRef] [PubMed]

35. Trichopoulou, A.; Martinez-Gonzalez, M.A.; Tong, T.Y.; Forouhi, N.G.; Khandelwal, S.; Prabhakaran, D.; Mozaffarian, D.; de Lorgeril, M. Definitions and potential health benefits of the Mediterranean diet: Views from experts around the world. BMC Med. 2014, 12, 112. [CrossRef] [PubMed]

36. Elia, A. La Rivoluzione Degli Integrali Buoni (Senza L'Aggiunta di Crusca o Fibre) (The Revolution of Good WholeGrains: Without Bran and Fibers Addition); Di Marsico Libri: Parepare, Italy, 2010; ISBN 8889979135.

37. Friedewald, W.T.; Levy, R.I.; Fredrickson, D.S. Estimation of the concentration of low-density lipoprotein cholesterol in plasma, without use of the preparative ultracentrifuge. Clin. Chem. 1972, 18, 499-502. [CrossRef] [PubMed]

38. Matthews, D.R.; Hosker, J.P.; Rudenski, A.S.; Naylor, B.A.; Treacher, D.F.; Turner, R.C. Homeostasis model assessment: Insulin resistance and beta-cell function from fasting plasma glucose and insulin concentrations in man. Diabetologia 1985, 28, 412-419. [CrossRef]

39. Jorgensen, A.B.; Frikke-Schmidt, R.; West, A.S.; Grande, P.; Nordestgaard, B.G.; Tybjaerg-Hansen, A. Genetically elevated non-fasting triglycerides and calculated remnant cholesterol as causal risk factors for myocardial infarction. Eur. Heart J. 2013, 34, 1826-1833. [CrossRef]

40. Alberti-Fidanza, A.; Fidanza, F. Mediterranean Adequacy Index of Italian diets. Public Health Nutr. 2004, 7 , 937-941. [CrossRef]

41. Alberti, A.; Fruttini, D.; Fidanza, F. The Mediterranean Adequacy Index: Further confirming results of validity. Nutr. Metab. Cardiovasc. Dis. NMCD 2009, 19,61-66. [CrossRef]

42. Third Report of the National Cholesterol Education Program (NCEP) Expert Panel on Detection, Evaluation, and Treatment of High Blood Cholesterol in Adults (Adult Treatment Panel III) final report. Circulation 2002, 106, 3143-3421. [CrossRef]

43. Romero-Gómez, M.; Zelber-Sagi, S.; Trenell, M. Treatment of NAFLD with diet, physical activity and exercise. J. Hepatol. 2017, 67, 829-846. [CrossRef] [PubMed]

44. Healthy Diet- World Health Organization. Available online: https://www.who.int/news-room/fact-sheets/ detail/healthy-diet (accessed on 12 May 2020).

45. Gomez-Marin, B.; Gomez-Delgado, F.; Lopez-Moreno, J.; Alcala-Diaz, J.F.; Jimenez-Lucena, R.; Torres-Pena, J.D.; Garcia-Rios, A.; Ortiz-Morales, A.M.; Yubero-Serrano, E.M.; Del Mar Malagon, M.; et al. Long-term consumption of a Mediterranean diet improves postprandial lipemia in patients with type 2 diabetes: The Cordioprev randomized trial. Am. J. Clin. Nutr. 2018, 108, 963-970. [CrossRef] [PubMed]

46. Roche, H.M. Fatty acids and the metabolic syndrome. Proc. Nutr. Soc. 2005, 64, 23-29. [CrossRef]

47. Rosenson, R.S.; Davidson, M.H.; Hirsh, B.J.; Kathiresan, S.; Gaudet, D. Genetics and causality of triglyceride-rich lipoproteins in atherosclerotic cardiovascular disease. J. Am. Coll. Cardiol. 2014, 64, 2525-2540. [CrossRef] [PubMed] 
48. Catapano, A.L.; Graham, I.; De Backer, G.; Wiklund, O.; Chapman, M.J.; Drexel, H.; Hoes, A.W.; Jennings, C.S.; Landmesser, U.; Pedersen, T.R.; et al. 2016 ESC/EAS Guidelines for the Management of Dyslipidaemias. Eur. Heart J. 2016, 37, 2999-3058. [CrossRef]

49. Eckel, R.H.; Jakicic, J.M.; Ard, J.D.; de Jesus, J.M.; Houston Miller, N.; Hubbard, V.S.; Lee, I.M.; Lichtenstein, A.H.; Loria, C.M.; Millen, B.E.; et al. 2013 AHA/ACC guideline on lifestyle management to reduce cardiovascular risk: A report of the American College of Cardiology/American Heart Association Task Force on Practice Guidelines. Circulation 2014, 129, S76-S99. [CrossRef]

50. Mente, A.; de Koning, L.; Shannon, H.S.; Anand, S.S. A systematic review of the evidence supporting a causal link between dietary factors and coronary heart disease. Arch. Intern. Med. 2009, 169, 659-669. [CrossRef]

51. Mensink, R.P.; Zock, P.L.; Kester, A.D.; Katan, M.B. Effects of dietary fatty acids and carbohydrates on the ratio of serum total to HDL cholesterol and on serum lipids and apolipoproteins: A meta-analysis of 60 controlled trials. Am. J. Clin. Nutr. 2003, 77, 1146-1155. [CrossRef]

52. Klop, B.; do Rego, A.T.; Cabezas, M.C. Alcohol and plasma triglycerides. Curr. Opin. Lipidol. 2013, 24, 321-326. [CrossRef]

53. Ko, G.J.; Kalantar-Zadeh, K.; Goldstein-Fuchs, J.; Rhee, C.M. Dietary Approaches in the Management of Diabetic Patients with Kidney Disease. Nutrients 2017, 9, 824. [CrossRef]

54. Shapiro, H.; Theilla, M.; Attal-Singer, J.; Singer, P. Effects of polyunsaturated fatty acid consumption in diabetic nephropathy. Nat. Rev. Nephrol. 2011, 7, 110-121. [CrossRef] [PubMed]

55. Ross, A.B.; Godin, J.P.; Minehira, K.; Kirwan, J.P. Increasing whole grain intake as part of prevention and treatment of nonalcoholic Fatty liver disease. Int. J. Endocrinol. 2013, 2013, 585876. [CrossRef] [PubMed]

56. Calinoiu, L.F.; Vodnar, D.C. Whole Grains and Phenolic Acids: A Review on Bioactivity, Functionality, Health Benefits and Bioavailability. Nutrients 2018, 10, 1615. [CrossRef] [PubMed]

57. Rose, D.J. Impact of whole grains on the gut microbiota: The next frontier for oats? Br. J. Nutr. 2014, 112, S44-S49. [CrossRef]

58. Federico, A.; Dallio, M.; Godos, J.; Loguercio, C.; Salomone, F. Targeting gut-liver axis for the treatment of nonalcoholic steatohepatitis: Translational and clinical evidence. Transl. Res. J. Lab. Clin. Med. 2016, 167, 116-124. [CrossRef]

59. Sandesara, P.B.; Virani, S.S.; Fazio, S.; Shapiro, M.D. The Forgotten Lipids: Triglycerides, Remnant Cholesterol, and Atherosclerotic Cardiovascular Disease Risk. Endocr. Rev. 2019, 40, 537-557. [CrossRef]

60. Maedler, K.; Oberholzer, J.; Bucher, P.; Spinas, G.A.; Donath, M.Y. Monounsaturated fatty acids prevent the deleterious effects of palmitate and high glucose on human pancreatic beta-cell turnover and function. Diabetes 2003, 52, 726-733. [CrossRef] [PubMed]

61. Varbo, A.; Freiberg, J.J.; Nordestgaard, B.G. Extreme nonfasting remnant cholesterol vs extreme LDL cholesterol as contributors to cardiovascular disease and all-cause mortality in 90000 individuals from the general population. Clin. Chem. 2015, 61, 533-543. [CrossRef]

62. Field, P.A.; Vasan, R.S. LDL-Cholesterol Is Not the Only Clinically Relevant Biomarker for Coronary Artery Disease or Acute Coronary Syndrome. Clin. Pharmacol. Ther. 2018, 104, 232-234. [CrossRef]

63. Leon-Acuna, A.; Alcala-Diaz, J.F.; Delgado-Lista, J.; Torres-Pena, J.D.; Lopez-Moreno, J.; Camargo, A.; Garcia-Rios, A.; Marin, C.; Gomez-Delgado, F.; Caballero, J.; et al. Hepatic insulin resistance both in prediabetic and diabetic patients determines postprandial lipoprotein metabolism: From the CORDIOPREV study. Cardiovasc. Diabetol. 2016, 15, 68. [CrossRef]

(C) 2020 by the authors. Licensee MDPI, Basel, Switzerland. This article is an open access article distributed under the terms and conditions of the Creative Commons Attribution (CC BY) license (http://creativecommons.org/licenses/by/4.0/). 